\begin{tabular}{|c|c|c|}
\hline \multirow{2}{*}{$\begin{array}{r}\text { Case Reports in } \\
\text { Gastroenterology }\end{array}$} & \multicolumn{2}{|c|}{ Case Rep Gastroenterol 2020;14:279-285 } \\
\hline & $\begin{array}{l}\text { DOI: 10.1159/000507649 } \\
\text { Published online: May 13, } 2020\end{array}$ & $\begin{array}{l}\text { (c) } 2020 \text { The Author(s) } \\
\text { Published by S. Karger AG, Basel } \\
\text { www.karger.com/crg }\end{array}$ \\
\hline & $\begin{array}{l}\text { This article is licensed under } \\
\text { International License (CC BY-N } \\
\text { Usage and distribution for comm }\end{array}$ & $\begin{array}{l}\text { mons Attribution-NonCommercial } 4.0 \\
\text { ger.com/Services/OpenAccessLicense). } \\
\text { guires written permission. }\end{array}$ \\
\hline
\end{tabular}

\title{
Cytomegalovirus Colitis with a Cobblestone Appearance
}

\author{
Kimitoshi Kubo ${ }^{a}$ Noriko Kimura ${ }^{b}$ Soichiro Matsuda ${ }^{a}$ Momoko Tsuda ${ }^{a}$ \\ Mototsugu Kato ${ }^{\mathrm{a}}$ \\ ${ }^{a}$ Department of Gastroenterology, National Hospital Organization Hakodate National \\ Hospital, Hakodate, Japan; 'bepartment of Pathology, National Hospital Organization \\ Hakodate National Hospital, Hakodate, Japan
}

\section{Keywords}

Cytomegalovirus colitis · Ulcer · Cobblestone appearance

\begin{abstract}
Cytomegalovirus (CMV) colitis with a cobblestone appearance is rare, and its endoscopic and pathological features remain poorly described. A 78-year-old woman was admitted to our hospital for disturbance of consciousness, high-grade fever, and diarrhea occurring up to 7 times a day. Sigmoidoscopy revealed a circumferential ulcer with mucosal defect, an ulcer with a cobblestone appearance extending from the upper rectum to the sigmoid colon, and an irregular ulcer on the lower rectum. She was histopathologically diagnosed with CMV colitis and intravenously treated with ganciclovir $(5 \mathrm{mg} / \mathrm{kg}$ ) for 7 weeks. Colonoscopy after treatment revealed an improvement of the ulcers extending from the rectum to the sigmoid colon, but no significant improvement of her general condition. She died from sepsis 4 months after hospitalization. To our knowledge, this report represents a valuable addition to the CMV literature describing a rare case of CMV colitis with a cobblestone appearance.
\end{abstract}




\section{Introduction}

Cytomegalovirus (CMV) colitis is known to occur mostly in immunocompromised and inflammatory bowel disease (IBD) patients and is associated with high mortality [1], while it is also reported to occur rarely in immunocompetent patients [2]. Endoscopic findings of CMV colitis are not specific, but punched-out ulceration is reported to have high sensitivity and specificity for CMV positivity [3, 4]. CMV colitis with a cobblestone appearance is rare, and its endoscopic and pathological features remain insufficiently elucidated.

We herein report a case of CMV colitis with a cobblestone appearance.

\section{Case Presentation}

A 78-year-old woman was admitted to our hospital for disturbance of consciousness, high-grade fever, and diarrhea occurring up to 7 times a day. She had a history of diabetes mellitus (DM). Physical examination findings included the following: height, $145 \mathrm{~cm}$; weight, $54 \mathrm{~kg}$; Glasgow Coma Scale, 8 (E3V1M4); blood pressure, 136/76 mm Hg; heart rate, $104 \mathrm{~min}$; and body temperature, $38.8^{\circ} \mathrm{C}$. Laboratory findings included: white blood cell count, $9.2 \times$ $10^{9} / \mathrm{L}$; C-reactive protein, $18.4 \mathrm{mg} / \mathrm{dL}$; serum protein, $5.5 \mathrm{~g} / \mathrm{dL}$; albumin, $2.6 \mathrm{~g} / \mathrm{dL}$; blood urea nitrogen, $39.9 \mathrm{mg} / \mathrm{dL}$; creatinine, $0.8 \mathrm{mg} / \mathrm{dL}$; glucose, $434 \mathrm{mg} / \mathrm{dL}$; and glycated hemoglobin, $7.9 \%$. Computed tomography revealed mild wall thickening extending from the rectum to the sigmoid colon (Fig. 1a, b). The patient started treatment with intravenous antibiotics as well as with insulin for glycemic control. One week later, the patient's consciousness improved and the frequency of diarrhea improved to 1-2 times/day, but the high-grade fever persisted. Repeated fecal cultures and Clostridium toxin tests were both negative and antibiotics were discontinued. Computed tomography on day 8 of hospitalization revealed a marked increase in wall thickening extending from the rectum to the sigmoid colon (Fig. 1c, d). Sigmoidoscopy on day 9 of hospitalization revealed a circumferential ulcer with mucosal defect, an ulcer with a cobblestone appearance extending from the upper rectum to the sigmoid colon (Fig. 2a-c), and an irregular ulcer on the lower rectum (Fig. 2d). A histopathologic examination of specimens from biopsies, performed for differential diagnosis of CMV colitis, ulcerative colitis, and ischemic colitis, showed only necrosis and granulation tissue. A second biopsy performed 1 week later revealed granulation tissue formation with high neutrophil infiltration (Fig. 2e).

Immunohistochemically, CMV-positive cells were observed (Fig. 2f); again, CMV antigen pp65 was negative, while anti-CMV IgM and IgG antibodies were positive.

The patient was diagnosed with CMV colitis and intravenously treated with ganciclovir $(5 \mathrm{mg} / \mathrm{kg}$ ) for 7 weeks. Colonoscopy after treatment revealed an improvement in the ulcers extending from the rectum to the sigmoid colon (Fig. 3a-d), but low-grade fever persisted with her performance status being 3 , suggesting no significant improvement of her general condition. She died from sepsis 4 months after hospitalization.

\section{Discussion/Conclusion}

The implications of our case are 2 -fold. First, CMV colitis may present a cobblestone appearance, while CMV colitis with a cobblestone appearance is rare and its endoscopic and pathological features remain poorly described in the literature. 
Endoscopic findings of CMV colitis are divided into mucosal and ulcerative changes, whose five features have been described by Suzuki et al. [3] as easy bleeding, loss of vascular pattern, mucosal edema, erythema, and mucinous exudates and as wide mucosal defect, punched-out ulceration, longitudinal ulceration, irregular ulceration, and cobblestone appearance, respectively. Of these, a cobblestone appearance has been defined as an aggregation of elevated lesions due to membrane changes, looking like half-spheres of a sub-pedunculated polyp with multiple ulcers, as seen in Crohn's disease. A recent study reported that the proportion of punched-out ulceration, irregular ulceration, and cobblestone appearance was significantly higher in ulcerative colitis patients with CMV colitis than in those patients without [4]. In addition, Le et al. [5] reported that ulceration was the most common endoscopic finding, with the cobblestone appearance found in 19.7\% (12/61) of patients with CMV colitis. Our patient had multiple ulcers, involving a mucosal defect and a cobblestone appearance and extending from the upper rectum to the sigmoid colon, and an irregular ulcer on the lower rectum. The mechanism of ulcer formation in CMV colitis has previously been accounted for by an ischemic change in the mucosal membrane caused by narrowing of the vascular lumen due to activation and proliferation of CMV in the vascular endothelial cells [6]. However, the mechanisms of formation of a cobblestone appearance in CMV colitis remain largely unknown.

While, currently, tissue diagnosis is the gold standard for the diagnosis of CMV colitis [7], in our case, the first 3 biopsies tested negative, with the diagnosis established only after the second 7 biopsies, in agreement with the report of McCurdy et al. [8] indicating that IBD patients require at least 10 biopsies to maintain a high probability of detecting CMV in colon tissue.

The second implication of interest is that CMV colitis occurred in an immunocompetent patient. In previous studies of CMV colitis in immunocompetent patients, the patient background (mean age, 61.1 years; DM, 13.6\% [6/44] [9]; mean age, 65.6 years; DM, 33.3\% [3/12] [10]; and mean age, 72.0 years; DM, 54.4\% [6/11] [2]) suggested that elderly patients with $\mathrm{DM}$ are also at risk for CMV colitis. In addition, one prospective study reported that CMV infection doubled the risk of mortality from DM (HR, 2.06; 95\%CI 1.05-4.06) [11]. Again, it has recently been reported that the in-hospital mortality and overall survival rates for CMV colitis patients without IBD are 29.5 and $60.7 \%$, respectively, with all patients dying from their poor general condition, such as septic shock, instead of CMV colitis itself. [5]. Our patient also died of sepsis due to her poor general condition but not from CMV colitis.

In conclusion, CMV colitis may present a cobblestone appearance, and clinicians should keep in mind that not only immunocompromised and IBD patients but also elderly patients with DM are at risk of developing CMV colitis.

\section{Statement of Ethics}

Written informed consent was obtained from the patient for the publication of this case report and any accompanying images.

\section{Disclosure Statement}

The authors have no conflicts of interest to disclose in association with this study. 


\section{Funding Sources}

No funding was obtained for this study.

\section{Author Contributions}

K.K., N.K., M.S., M.T., and M.K. carried out and confirmed the diagnosis, provided the details of the case and contributed to the design of the report. K.K. and M.K. drafted the manuscript. All authors read and approved the final version of the manuscript.

\section{References}

1 Nakase H, Herfarth H. Cytomegalovirus colitis, cytomegalovirus hepatitis and systemic cytomegalovirus infection: common features and differences. Inflamm Intest Dis. 2016 Apr;1(1):15-23.

2 Lee CY, Chen YH, Lu PL. Reactivated cytomegalovirus proctitis in an immunocompetent patient presenting as nosocomial diarrhea: a case report and literature review. BMC Infect Dis. 2017 Feb;17(1):113.

3 Suzuki H, Kato J, Kuriyama M, Hiraoka S, Kuwaki K, Yamamoto K. Specific endoscopic features of ulcerative colitis complicated by cytomegalovirus infection. World J Gastroenterol. 2010 Mar;16(10):1245-51.

4 Yang H, Zhou W, Lv H, Wu D, Feng Y, Shu H, et al. The association between CMV viremia or endoscopic features and histopathological characteristics of CMV colitis in patients with underlying ulcerative colitis. Inflamm Bowel Dis. 2017 May;23(5):814-21.

5 Le PH, Kuo CJ, Wu RC, Hsu JT, Su MY, Lin CJ, et al. Pancolitis associated with higher mortality risk of cytomegalovirus colitis in patients without inflammatory bowel disease. Ther Clin Risk Manag. 2018 Aug;14:1445-51.

6 Iwasaki T. Alimentary tract lesions in cytomegalovirus infection. Acta Pathol Jpn. 1987 Apr;37(4):549-65. Japanese.

7 Juric-Sekhar G, Upton MP, Swanson PE, Westerhoff M. Cytomegalovirus (CMV) in gastrointestinal mucosal biopsies: should a pathologist perform CMV immunohistochemistry if the clinician requests it? Hum Pathol. 2017 Feb;60:11-5.

8 McCurdy JD, Enders FT, Jones A, Killian JM, Loftus EV Jr, Bruining DH, et al. Detection of cytomegalovirus in patients with inflammatory bowel disease: where to biopsy and how many biopsies. Inflamm Bowel Dis. 2015 Dec;21(12):2833-8.

9 Galiatsatos P, Shrier I, Lamoureux E, Szilagyi A. Meta-analysis of outcome of cytomegalovirus colitis in immunocompetent hosts. Dig Dis Sci. 2005 Apr;50(4):609-16.

10 Seo TH, Kim JH, Ko SY, Hong SN, Lee SY, Sung IK, et al. Cytomegalovirus colitis in immunocompetent patients: a clinical and endoscopic study. Hepatogastroenterology. 2012 Oct;59(119):2137-41.

11 Mendy A, Gasana J, Vieira ER, Diallo H. Prospective study of cytomegalovirus seropositivity and risk of mortality from diabetes. Acta Diabetol. 2014 0ct;51(5):723-9. 


\section{Case Reports in \\ Gastroenterology}

\begin{tabular}{l|l}
\hline Case Rep Gastroenterol 2020;14:279-285 \\
\hline DOI: 10.1159/000507649 & $\begin{array}{l}\odot \text { 2020 The Author(s). Published by S. Karger AG, Basel } \\
\text { www.karger.com/crg }\end{array}$ \\
\hline
\end{tabular}

Kubo et al.: Cytomegalovirus Colitis with a Cobblestone Appearance
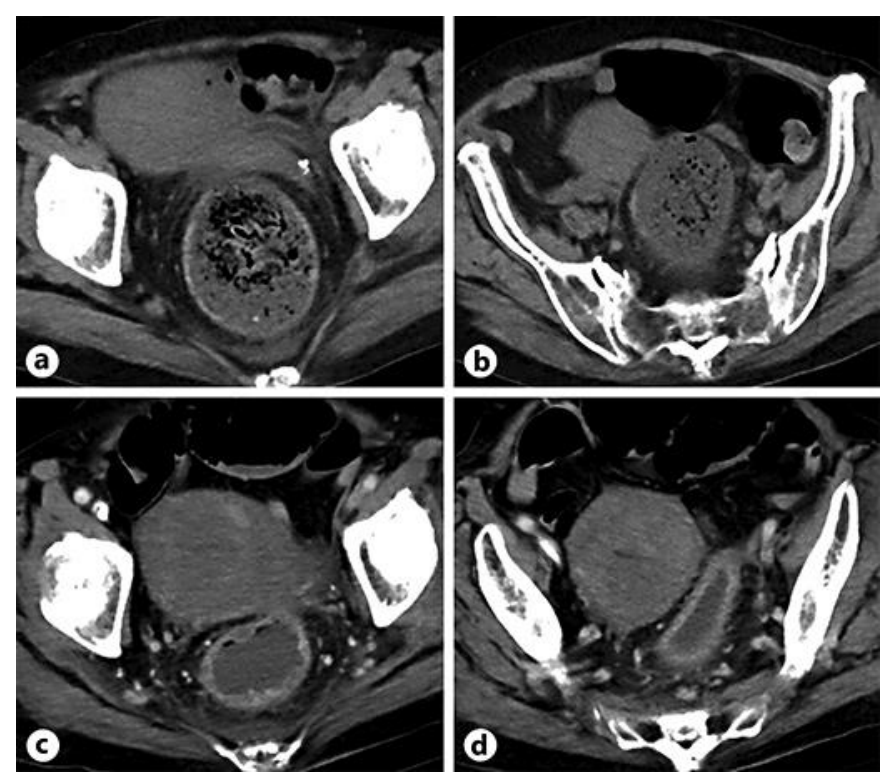

Fig. 1. Computed tomography (CT). a, b CT on admission revealed mild wall thickening extending from the rectum to the sigmoid colon. c, $\mathbf{d}$ CT on day 8 of hospitalization revealed severe wall thickening extending from the rectum to the sigmoid colon. 


\section{Case Reports in Gastroenterology}

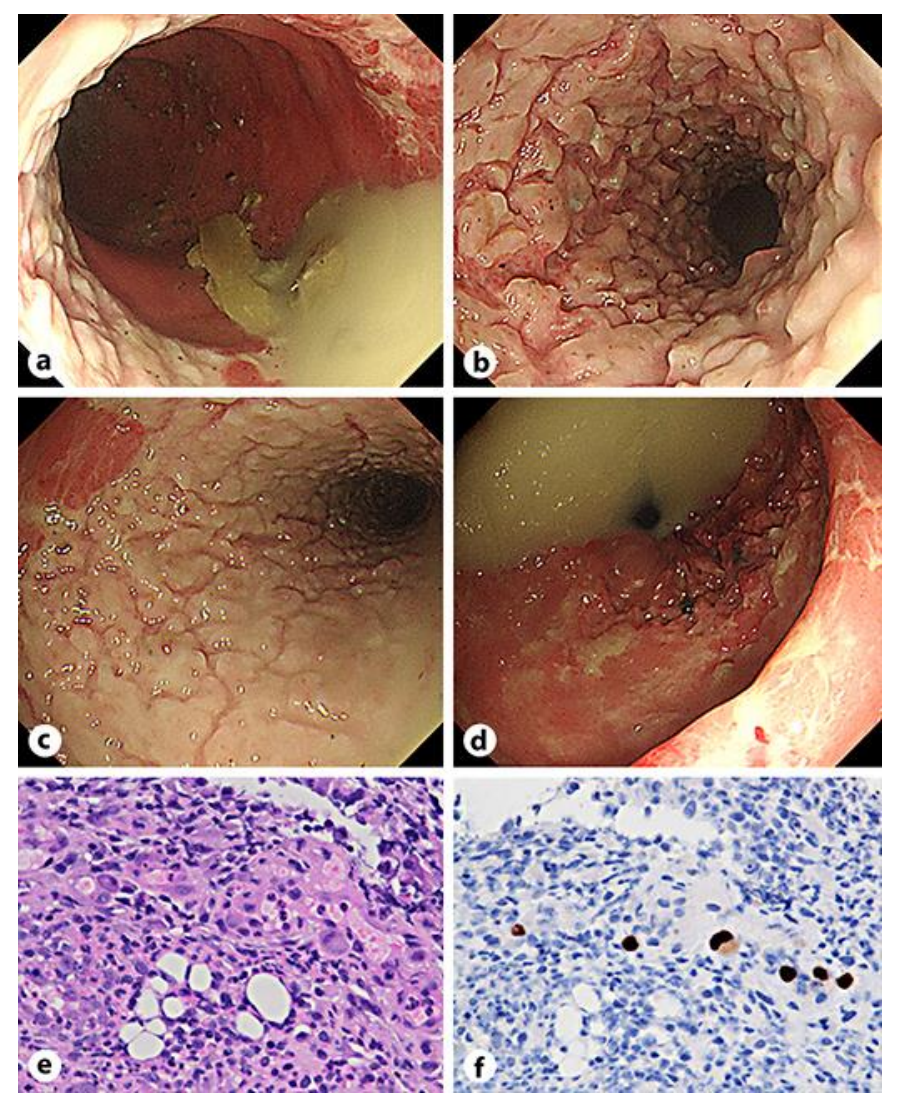

Fig. 2. Endoscopic findings and a histopathologic examination of the biopsy specimens. Sigmoidoscopy revealed a circumferential ulcer with mucosal defect and a cobblestone appearance extending from the upper rectum to the sigmoid colon (a-c) and an irregular ulcer on the lower rectum (d). e H\&E staining showed formation of granulation tissue with high neutrophil infiltration. $\times 400 . f$ Immunohistochemistry was positive for cytomegalovirus. $\times 400$. 


\section{Case Reports in \\ Gastroenterology}

\begin{tabular}{l|l}
\hline Case Rep Gastroenterol 2020;14:279-285 \\
\hline DOI: 10.1159/000507649 & $\begin{array}{l}\text { @ 2020 The Author(s). Published by S. Karger AG, Basel } \\
\text { www.karger.com/crg }\end{array}$ \\
\hline
\end{tabular}

Kubo et al.: Cytomegalovirus Colitis with a Cobblestone Appearance
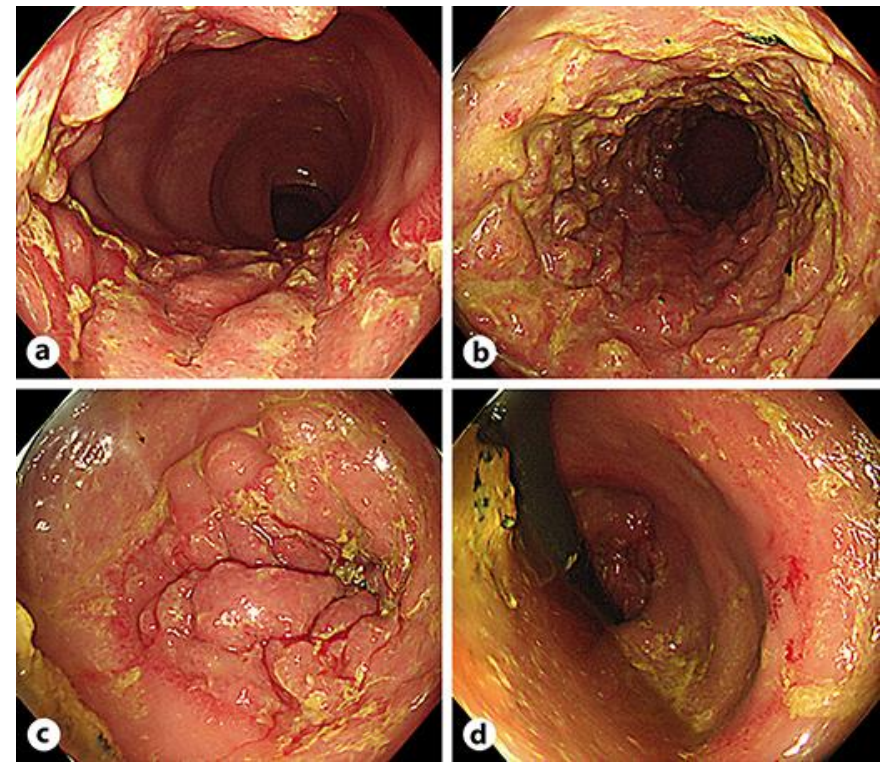

Fig. 3. Endoscopic findings after treatment. a-d Colonoscopy after treatment revealed an improvement in the ulcers extending from the rectum to the sigmoid colon. 